\title{
Principais diagnósticos e intervenções de enfermagem no manejo da covid-19 do cuidado primário à alta complexidade
}

\author{
Management of adherence to chronic diseases treatments: experiences of Community Health \\ Workers
}

Principales diagnósticos e intervenciones de enfermería en el manejo de covid-19 desde atención primaria hasta alta complejidad

\author{
Jorge Luiz Lima da Silva ${ }^{*}$, Camille Rabello Ramos², Miriam da Costa Lindolpho ${ }^{3}$, Ana Luísa de \\ Oliveira Lima ${ }^{4}$, Larissa Murta Abreu ${ }^{5}$, Fernanda Karolinne Rampe de Oliveira ${ }^{6}$.
}

Como citar esse artigo. da Silva, JLL; Ramos, CR; Lindolpho, MC; Lima, ALO; Abreu, LM; de Oliveira, FKR. Principais diagnósticos e intervenções de enfermagem no manejo da covid-19 do cuidado primário à alta complexidade. Revista Pró-UniverSUS. 2021 Jan./Jun.; 12 (1): $27-36$.

\section{Resumo}

Introdução: no final do ano de 2019, tomou-se conhecimento a nova doença viral (covid-19) que se demonstrou um problema de saúde a medida que milhares de indivíduos foram acometidos. Dessa forma, faz-se necessário elencar diagnósticos de enfermagem relacionados ao manejo dos pacientes com a doença. Materiais e Métodos: trata-se de uma pesquisa de revisão integrativa de caráter descritivo, que se deu sobre análise da produção científica de enfermagem, baseada em obras secundárias disponibilizadas. Resultados: foram elaborados quadros que apresentam o levantamento dos principais diagnósticos e suas respectivas intervenções em quatro categorias a serem discutidas, sendo: I- diagnósticos levantados para a população brasileira em risco; II- diagnósticos levantados para a população com déficit de conhecimento; III- diagnósticos levantados para o paciente infectado pela covid-19; IV- diagnósticos levantados para a população infectada e com complicações agudas da covid-19. Discussão: os diagnósticos e as intervenções apresentadas representam um subsídio para os problemas encontrados na prática clínica, representando a importância da produção bibliográfica sobre o tema. Considerações finais: identificaram os principais diagnósticos de enfermagem atribuídos aos pacientes de covid-19, destacando para cada diagnóstico elencado suas respectivas intervenções, frisando a necessidade de avaliar particularmente os casos e cenários que podem existir, durante a prática clínica do enfermeiro nos diferentes níveis de atenção.

Palavras-chave: Processo de Enfermagem; Assistência de Enfermagem; Diagnóstico de Enfermagem; Cuidados de Enfermagem; Infecções por Coronavírus.

\begin{abstract}
Introduction: at the end of 2019, the new viral disease (covid-19) became known, which proved to be a health problem as thousands of individuals were affected. Thus, it is necessary to list nursing diagnoses related to the management of patients with the disease. Materials \& Methods: this is an integrative review research of a descriptive character, which took place on the analysis of scientific nursing production, based on available secondary works. Results: tables were prepared that present a survey of the main diagnoses and their respective interventions in four categories to be discussed, as follows: I- diagnoses raised for the Brazilian population at risk; II- diagnoses raised for the population with a knowledge deficit; III- diagnoses raised for the patient infected by covid-19; IV- diagnoses raised for the infected population and with acute complications of covid-19. Discussion: the diagnoses and interventions presented represent a subsidy for the problems encountered in clinical practice, representing the importance of bibliographic production on the subject. Final considerations: the main nursing diagnoses attributed to covid-19 patients were identified, highlighting for each diagnosis listed their respective interventions, emphasizing the need to evaluate particularly the cases and scenarios that may exist, during the nurse's clinical practice at different levels of attention.
\end{abstract}

Keywords: Nursing Process; Nursing Assistance; Nursing Diagnosis; Nursing Care; Coronavirus Infections.

$1^{1 *}$ Doutor. Docente, Programa de Pós-graduação em Saúde Coletiva/Universidade Federal Fluminense/Niterói/Rio de Janeiro/Brasil. ORCID: http://orcid.org/0000-0002-2370-6343.

${ }^{2}$ Enfermeira, Centro de Atenção à Saúde do Idoso e seus Cuidadores (CASIC)/Universidade Federal Fluminense/Niterói/Rio de Janeiro/Brasil. ORCID: https://orcid.org/0000-0003$1360-3743$

${ }^{3}$ Doutor. Docente, Escola de Enfermagem Aurora de Afonso Costa/Universidade Federal Fluminense/Niterói/Rio de Janeiro/Brasil. ORCID: https://orcid.org/0000-0002-2503-4827.

${ }^{4}$ Discente, Escola de Enfermagem Aurora de Afonso Costa/Universidade Federal Fluminense/Niterói/Rio de Janeiro/Brasil. ORCID: https://orcid.org/0000-0001-6539-8855.

${ }_{5}^{5}$ Discente, Escola de Enfermagem Aurora de Afonso Costa/Universidade Federal Fluminense//Niterói/Rio de Janeiro/Brasil. ORCID: https://orcid.org/0000-0002-7119-4370.

${ }^{6}$ Discente, Escola de Enfermagem Aurora de Afonso Costa/Universidade Federal Fluminense/ Niterói/Rio de Janeiro/Brasil. fernanda_rampe@live.com ORCID: https://orcid. org/0000-0003-3176-5383. 


\section{Resumen}

Introducción: a finales de 2019 se conoció la nueva enfermedad viral (covid-19), que resultó ser un problema de salud ya que miles de personas se vieron afectadas. Por tanto, es necesario enumerar los diagnósticos de enfermería relacionados con el manejo de los pacientes con la enfermedad. Materiales y Métodos: se trata de una investigación de revisión integradora de carácter descriptivo, que tuvo lugar en el análisis de la producción científica de enfermería, basada en trabajos secundarios disponibles. Resultados: se prepararon tablas que presentan una encuesta de los principales diagnósticos y sus respectivas intervenciones en cuatro categorías para ser discutidas, como sigue: I- diagnósticos planteados para la población brasileña en riesgo; II- diagnósticos planteados para la población con un déficit de conocimiento; III- diagnósticos planteados para el paciente infectado por covid-19; IV- diagnósticos planteados para la población infectada y con complicaciones agudas de covid19. Discusión: los diagnósticos e intervenciones presentados representan un subsidio a los problemas encontrados en la práctica clínica, representando la importancia de la producción bibliográfica sobre el tema. Consideraciones finales: se identificaron los principales diagnósticos de enfermería atribuidos a pacientes de covid-19, destacando para cada diagnóstico enumerados sus respectivas intervenciones, enfatizando la necesidad de evaluar particularmente los casos y escenarios que pueden existir, durante la práctica clínica de la enfermera en diferentes niveles de atención.

Palabras clave: Proceso de Enfermería; Asistencia de Enfermería; Diagnóstico de Enfermería; Cuidado de Enfermera; Infecciones por Coronavirus.

\section{Introdução}

No final do ano de 2019, tomou-se conhecimento a nova doença viral que atingiu o povoado de Wuhan, província chinesa. Aquilo que parecia uma afecção respiratória de origem viral ordinária veio a apresentarse como um crítico transtorno de saúde coletiva e, em curto período de tempo, viria a ser a maior pandemia que este século viveu ${ }^{1,2}$.

Mediante a pesquisa do código genético viral, apontou-seumnovotipo de betacoronavírus, inicialmente chamado 2019-nCoV ou SARS-CoV-2 (do inglês Severe Acute Respiratory Syndrome Coronavirus). À doença causada por este micro-organismo, chamou-se covid19, que possui como clínica predominante sintomas como febre, fadiga e tosse seca, que podem evoluir para dispneia e, em casos mais graves, Síndrome Respiratória Aguda Grave (SRAG) ${ }^{2,3}$.

A intensa capacidade da doença para propagarse, bem como a gravidade de suas repercussões em todos os países atingidos foram tão importantes a ponto da Organização Mundial da Saúde (OMS) declarar emergência de saúde global e, em poucos dias considerála como pandemia ${ }^{4}$.

Dado esse cenário, faz-se necessário correlacionar as informações pertinentes à covid-19 divulgadas pelos órgãos brasileiros competentes com os principais diagnósticos de enfermagem, suas respectivas intervenções e atividades, que sustentarão a práxis desses profissionais, em diversos cenários e níveis de atenção servindo, como modelo de estudo, reflexão e discussão para os enfermeiros. Destaca-se o fato de não ter estabelecido ordem de prioridade, nem definido metas de resultados esperados, que deverão ser pensadas pelo enfermeiro em seu contexto original e carregado de singularidades.

Os diagnósticos de enfermagem são subsidiados pelas respostas dos sujeitos aos processos da vida e/ ou problemas de saúde. Para que tais diagnósticos de enfermagem sejam validados, é preciso experiência de um enfermeiro para a identificação e análise dos indicadores diagnósticos (fatores de risco / fatores relacionados / características definidoras), bem como, para priorizar, prescrever intervenções de enfermagem e indicar que atividades serão melhores para alcance dos objetivos, faz-se imprescindível fundamentada sapiência e destreza para inter-relacionar os dados coletados, achados clínico-laboratoriais-epidemiológicos e evidências científicas que amparem seu julgamento e tomada de decisão $0^{5,6,7,8}$.

Diante do exposto, o estudo tem por objetivo elencar os principais diagnósticos e intervenções de enfermagem em vigência da pandemia de covid-19, com vistas a promover o manejo adequado desses pacientes e subsidiar a atuação da enfermagem de acordo com o contexto apresentado.

\section{Materiais e Métodos}

Trata-se de uma pesquisa de revisão integrativa de caráter descritivo, que se deu a partir da análise da produção científica de enfermagem, baseada em obras secundárias disponibilizadas. A coleta do material para pesquisa ocorreu no mês de maio de 2020 .

O levantamento foi realizado em ambiente virtual na Biblioteca Virtual de Saúde (BVS), nas bases de dados Scielo (Scientific Eletronic Library Online), PubMed (National Library of Medicine) e Lilacs (Literatura Latino-Americana em Ciências da Saúde). Os artigos foram incluídos nos resultados de busca com os seguintes descritores: "diagnóstico de enfermagem" e "covid-19" combinados entre si por meio do operador booleano "and" estes termos foram utilizados de forma conjunta e isolados. As obras identificadas duplicadas, em bases diferentes, foram eliminadas, considerandose seu primeiro registro. Também foi realizado levantamento bibliográfico por meio de busca livre. 
Foram consultados manuais, livros e guias, que, devido à sua relevância, foram aproveitados.

Selecionou-se, então, artigos que demonstraram os principais diagnósticos de enfermagem, de acordo com a taxonomia NANDA I 2018-20207. Mediante a infecção por $S A R S-C o V-2$ e as atividades a eles pertinentes, de acordo com a Classificação das Intervenções de Enfermagem (NIC) ${ }^{8}$, foram correlacionados com as diretrizes para diagnóstico e tratamento da covid-19, e o protocolo de manejo clínico da covid-19 na atenção especializada, ambos do Ministério da Saúde.

Primeiramente, as obras foram armazenadas, para que em seguida fosse realizada a pré-seleção mediante a leitura dos títulos e resumos. Nessa fase, buscou-se a relação entre o conteúdo, título, resumo, e se atendiam ao objeto de estudo. $\mathrm{Na}$ fase de seleção, as obras foram lidas na íntegra com atenção especial para os resultados, discussão e conclusões. Aquelas que abordaram diagnósticos e intervenções de enfermagem foram selecionadas. As informações foram organizadas em quadro no tópico de resultados para discussão, de acordo com análise prévia dos manuscritos.

\section{Resultados}

Para descrição dos resultados foram elaborados quadros que apresentam o levantamento dos principais diagnósticos e respectivas intervenções, levando-se em consideração a população em risco, a infectada pela covid-19, e infectadas com complicações da doença, como exposto nos quadros 1 a 4 .

Após a análise dos artigos, manuais e documentos complementares eleitos para o estudo, foram desenvolvidas quatro categorias a serem discutidas: I- diagnósticos levantados para a população brasileira em risco; II- diagnósticos levantados para a população com déficit de conhecimento; III- diagnósticos levantados para o paciente infectado pela covid-19; IVdiagnósticos levantados para a população infectada e com complicações agudas da covid-19.

\section{Discussão}

O primeiro caso da covid-19 no Brasil foi noticiado nofinal de fevereirode 2020. Visando monitorar e reduzir o avanço e a disseminação da doença, a OMS desenvolveu protocolos baseados na experiência com a Síndrome Respiratória do Oriente Médio (MERS) e a Síndrome Respiratória Aguda Grave (SARS). Nesses, são recomendadas intervenções de controle para reduzir o risco geral de transmissão da covid-19, entre estas se destaca a lavagem frequente das mãos, especialmente após contato direto com pessoas doentes ou seu meio ambiente .
Entretanto, aproximadamente 18,4 milhões de brasileiros não recebem água encanada diariamente, como revelado pelo IBGE no ano de $2019^{10,11}, 35$ milhões de pessoas sem água tratada e 100 milhões sem coleta de esgoto ${ }^{12}$.

Logo, a adesão da lavagem das mãos não ocorre de forma universal no Brasil. Tais dados demonstram que o País já enfrentava uma crise sanitária antes da covid-196,13,14.

O enfermeiro é o profissional que contempla as dimensões holísticas do ser, e responsável pelo processo de enfermagem. O processo de enfermagem é o método utilizado para sistematização do cuidado, proporcionando condições para administrar a assistência de maneira individualizada, permitindo maior integração entre enfermeiro e paciente, sua rede de apoio e equipe de saúde ${ }^{15}$. A sistematização ocorre em etapas, sendo elas, coleta de dados, diagnóstico de enfermagem, planejamento, implementação e avaliação ${ }^{6}$.

O diagnóstico de enfermagem resulta da análise clínica realizada pelo enfermeiro a partir da resposta humana às condições de saúde, vida ou vulnerabilidade, podendo ser de um indivíduo ou grupo. Concentrase nas características definidoras, que são inferências observáveis, que unem-se como manifestações de um diagnóstico com foco no problema de saúde ${ }^{7}$. Apenas o enfermeiro poderá avaliar e, se necessário, reajustar tais intervenções de modo alcançar os objetivos desejados ${ }^{7,8}$.

Devido a sua natureza recente, o estudo apresenta escassez de materiais bibliográficos desenvolvidos durante a vivência da pandemia do novo coronavírus, incluindo aqueles com a melhor evidência científica disponível. Dessa forma, levanta-se a necessidade de publicação e abordagem constante do tema nos ambientes plurais da sociedade, de forma a difundir o conhecimento até o momento consolidado.

\section{Diagnósticos levantados para a população brasileira em risco}

Nesta etapa, levantaram-se quatro diagnósticos e possíveis intervenções para cada um, em relação ao alvo do cuidado, que se encontra vulnerável à infecção pela covid-19 sem, no entanto, ter, necessariamente, ocorrido contato com o agente infeccioso.

No domínio promoção da saúde, foi identificado o diagnóstico de enfermagem de "saúde deficiente da comunidade" devidoà situação pandêmica. Com objetivo de fornecer o cuidado direcionado às necessidades impostas por esse cenário, algumas intervenções de enfermagem podem ser utilizadas: determinar a população-alvo para a avaliação médica, obter amostras para análise como swab nasal e orofaríngeo, e sangue, fornecer contato para seguimento dos pacientes com 
Quadro 1. Distribuição dos artigos incluídos na revisão.

\begin{tabular}{|c|c|c|c|}
\hline $\begin{array}{l}\text { DIAGNÓSTICO DE } \\
\text { ENFERMAGEM }\end{array}$ & DEFINIÇÃO & INTERVENÇÕES & RESULTADOS \\
\hline $\begin{array}{l}\text { Saúde deficiente da } \\
\text { comunidade relaciona- } \\
\text { da à disseminação da } \\
\text { covid-19 caracterizada } \\
\text { pelo problema de saúde } \\
\text { vivenciado pela popu- } \\
\text { lação mundial. }\end{array}$ & $\begin{array}{l}\text { Presença de um ou mais } \\
\text { problemas de saúde ou } \\
\text { fatores que impedem o } \\
\text { bem-estar ou aumentam } \\
\text { o risco de problemas de } \\
\text { saúde vivenciados por } \\
\text { um grupo. }\end{array}$ & $\begin{array}{l}\text { Avaliação de saúde. } \\
\text { Controle do ambiente: comuni- } \\
\text { dade. } \\
\text { Desenvolvimento da saúde co- } \\
\text { munitária. } \\
\text { Desenvolvimento de programa } \\
\text { de saúde } \\
\text { Educação em Saúde. } \\
\text { Marketing social. } \\
\text { Melhora na educação em saúde. } \\
\text { Supervisão: comunidade. }\end{array}$ & $\begin{array}{l}\text { Controle de risco comunitário: doenças contagio- } \\
\text { sas. } \\
\text { Definição: ações comunitárias para eliminar ou } \\
\text { reduzir a propagação de agentes infecciosos que } \\
\text { ameaçam a saúde pública. } \\
\text { Parâmetros: } \\
\text { ( ) Pobre; } \\
\text { ( ) Razoável; } \\
\text { () Bom; } \\
\text { () Muito bom; } \\
\text { () Excelente. }\end{array}$ \\
\hline $\begin{array}{l}\text { Risco de infecção re- } \\
\text { lacionado ao conhe- } \\
\text { cimento insuficiente } \\
\text { para evitar exposição } \\
\text { ao patógeno e à invasão } \\
\text { do micro-organismo } \\
\text { SARS-CoV-2. }\end{array}$ & $\begin{array}{l}\text { Suscetibilidade à inva- } \\
\text { são e multiplicação de } \\
\text { organismos patogênicos } \\
\text { que pode comprometer a } \\
\text { saúde. }\end{array}$ & $\begin{array}{l}\text { Controle de doenças transmissí- } \\
\text { veis. } \\
\text { Controle de infecção. } \\
\text { Proteção contra infecção }\end{array}$ & $\begin{array}{l}\text { Conhecimento: controle da doença aguda. } \\
\text { Definição: extensão da compreensão sobre uma } \\
\text { doença reversível, seu tratamento e prevenção de } \\
\text { complicações. } \\
\text { Indicadores a serem avaliados: benefícios do con- } \\
\text { trole da doença, sinais e sintomas da doença; sinais } \\
\text { e sintomas das complicações; estratégias para evi- } \\
\text { tar exposição dos outros à doença; fontes respeitá- } \\
\text { veis de informação sobre a doença; saber quando } \\
\text { obtiver ajuda de um profissional de saúde. } \\
\text { Parâmetros: } \\
\text { () Nenhum conhecimento; } \\
\text { () Conhecimento limitado; } \\
\text { () Conhecimento moderado; } \\
\text { () Conhecimento substancial; } \\
\text { () Conhecimento vasto. }\end{array}$ \\
\hline $\begin{array}{l}\text { Isolamento social rela- } \\
\text { cionado à necessidade } \\
\text { de controle de disse- } \\
\text { minação do micro-or- } \\
\text { ganismo SARS-CoV-2 } \\
\text { caracterizado por dis- } \\
\text { tanciamento social e } \\
\text { quarentena. }\end{array}$ & $\begin{array}{l}\text { Solidão sentida pelo indi- } \\
\text { víduo e percebida como } \\
\text { imposta por outros e } \\
\text { como um estado negativo } \\
\text { ou ameaçador. }\end{array}$ & $\begin{array}{l}\text { Aconselhamento. } \\
\text { Apoio emocional. } \\
\text { Controle do peso. } \\
\text { Construção de relação comple- } \\
\text { xa. } \\
\text { Controle do comportamento. } \\
\text { Escuta ativa. } \\
\text { Estabelecimento de limites. } \\
\text { Melhora da autopercepção. }\end{array}$ & $\begin{array}{l}\text { Adaptação à mudança. } \\
\text { Definição: resposta emocional e comportamental } \\
\text { adaptativa de um indivíduo com a função cognitiva } \\
\text { intacta a uma mudança necessária no ambiente de } \\
\text { vida. } \\
\text { Indicadores a serem avaliados: expressa satisfação } \\
\text { com rotina diária; expressa satisfação com nível de } \\
\text { independência; expressa satisfação com os arranjos } \\
\text { de vida; exibe humor positivo; parece satisfeito; } \\
\text { respeita direitos de outras pessoas; mantém rela- } \\
\text { ções positivas. } \\
\text { Parâmetros: } \\
\text { () Nunca demonstrado; } \\
\text { () Raramente demonstrado; } \\
\text { () Algumas vezes demonstrado; } \\
\text { () Frequentemente demonstrado; } \\
\text { () Consistentemente demonstrado. }\end{array}$ \\
\hline $\begin{array}{l}\text { Risco de solidão rela- } \\
\text { cionado ao isolamento } \\
\text { social. }\end{array}$ & $\begin{array}{l}\text { Suscetibilidade a des- } \\
\text { conforto associado ao } \\
\text { desejo ou necessidade de } \\
\text { ter mais contato com os } \\
\text { outros que pode compro- } \\
\text { meter a saúde. }\end{array}$ & $\begin{array}{l}\text { Apoio ao cuidador. } \\
\text { Apoio familiar. } \\
\text { Arteterapia. } \\
\text { Controle do humor. } \\
\text { Grupo de apoio. } \\
\text { Manutenção do processo fami- } \\
\text { liar. } \\
\text { Melhora do sistema de apoio. } \\
\text { Promoção da esperança. } \\
\text { Redução da ansiedade. } \\
\text { Terapia recreacional. } \\
\text { Treinamento da assertividade. }\end{array}$ & $\begin{array}{l}\text { Gravidade da solidão. } \\
\text { Definição: gravidade dos sinais e sintomas de iso- } \\
\text { lamento emocional, social ou existencial. } \\
\text { Indicadores a serem avaliados: sensação de deses- } \\
\text { perança; sentimento de perda decorrente da separa- } \\
\text { ção de outra pessoa; sensação de não ser compreen- } \\
\text { dido; sensação de ser excluído; sensação de que o } \\
\text { tempo parece interminável; dificuldade de planeja- } \\
\text { mento; dificuldade de superar separação; oscilação } \\
\text { de humor; concentração prejudicada; depressão. } \\
\text { Parâmetros: } \\
\text { () Grave; } \\
\text { ( ) Substancial; } \\
\text { ( ) Moderado; } \\
\text { () Leve; } \\
\text { ( ) Nenhum. }\end{array}$ \\
\hline
\end{tabular}


Quadro 2. Levantamento dos principais diagnósticos atribuídos à população com déficit de conhecimento.

\begin{tabular}{|c|c|c|c|}
\hline $\begin{array}{l}\text { DIAGNÓSTICO DE } \\
\text { ENFERMAGEM }\end{array}$ & DEFINIÇÃO & INTERVENÇÕES & RESULTADOS \\
\hline $\begin{array}{l}\text { Enfrentamento ineficaz } \\
\text { relacionado à avaliação } \\
\text { imprecisa de ameaças } \\
\text { caracterizada por com- } \\
\text { portamento destrutivo } \\
\text { em relação a si mesmo } \\
\text { e aos outros. }\end{array}$ & $\begin{array}{l}\text { Padrão de avaliação in- } \\
\text { válida de estressores, } \\
\text { com esforços cognitivos } \\
\text { e/ou comportamentais, } \\
\text { que falha em controlar } \\
\text { as demandas relativas ao } \\
\text { bem-estar. }\end{array}$ & $\begin{array}{l}\text { Apoio ao sustento. } \\
\text { Controle de ideias delirantes. } \\
\text { Ensino. } \\
\text { Facilitação da autorresponsabi- } \\
\text { lidade. } \\
\text { Melhora das habilidades de } \\
\text { vida. } \\
\text { Modificação do comportamento. }\end{array}$ & $\begin{array}{l}\text { Crenças de saúde: ameaça percebida. } \\
\text { Definição: convicção pessoal de que um problema } \\
\text { que ameaça a saúde é grave, com potencial para } \\
\text { consequências negativas ao estilo de vida. } \\
\text { Domínio - Conhecimento e Comportamento em } \\
\text { Saúde (IV); Classe - Crenças em Saúde (R); } \\
\text { Indicadores a serem avaliados: Ameaça percebida à } \\
\text { saúde; preocupação relativa à doença; preocupação } \\
\text { relativa a potenciais complicações; gravidade per- } \\
\text { cebida da doença; gravidade percebida das compli- } \\
\text { cações; impacto percebido no atual estilo de vida; } \\
\text { risco de morte percebido. } \\
\text { Parâmetros: } \\
\text { () Muito fraco; } \\
\text { ( ) Fraco; } \\
\text { () Moderado; } \\
\text { ( ) Forte ; } \\
\text { () Muito forte. }\end{array}$ \\
\hline
\end{tabular}


Quadro 3 (cont.). Levantamento dos principais diagnósticos atribuídos ao paciente infectado pela covid-19.

\begin{tabular}{|c|c|c|c|}
\hline $\begin{array}{c}\text { DIAGNÓSTICO DE } \\
\text { ENFERMAGEM }\end{array}$ & DEFINIÇÃO & $\begin{array}{l}\text { INTERVENÇÕES DE } \\
\text { ENFERMAGEM }\end{array}$ & RESULTADOS \\
\hline $\begin{array}{l}\text { Troca de gases pre- } \\
\text { judicada relacionada } \\
\text { à infecção respirató- } \\
\text { ria caracterizada por } \\
\text { dispneia, gasometria } \\
\text { arterial anormal, hiper- } \\
\text { capnia, hipoxemia e/ou } \\
\text { hipóxia. }\end{array}$ & $\begin{array}{l}\text { Excesso ou déficit na } \\
\text { oxigenação e/ou na eli- } \\
\text { minação de dióxido de } \\
\text { carbono na membrana } \\
\text { alveolocapilar. }\end{array}$ & $\begin{array}{l}\text { Assistência ventilatória. } \\
\text { Controle ácido-básico. } \\
\text { Controle do choque. }\end{array}$ & $\begin{array}{l}\text { Estado respiratório: troca gasosa. } \\
\text { Definição: troca alveolar de dióxido de carbono e } \\
\text { oxigênio para manter as concentrações de gases do } \\
\text { sangue arterial. } \\
\text { Indicadores a serem avaliados: saturação de oxi- } \\
\text { gênio; achados na radiografia de tórax; equilíbrio } \\
\text { ventilação-perfusão; pressão parcial de oxigênio no } \\
\text { sangue arterial; pressão parcial de dióxido de car- } \\
\text { bono; pH arterial, dióxido de carbono expirado. } \\
\text { Parâmetros: } \\
\text { ( )Desvio grave da variação normal; } \\
\text { ( ) Desvio substancial da variação normal; } \\
\text { ( ) Desvio moderado da variação normal; } \\
\text { ( ) Leve desvio da variação normal ; } \\
\text { ( ) Sem desvio da variação normal. } \\
\text { Outros indicadores passíveis de serem avaliados: } \\
\text { dispneia em repouso; dispneia com esforço leve; } \\
\text { inquietação; cianose; sonolência. } \\
\text { Parâmetros: } \\
\text { ( ) Grave; } \\
\text { () Substancial; } \\
\text { ( ) Moderado; } \\
\text { ( ) Leve; } \\
\text { ( ) Nenhum. }\end{array}$ \\
\hline $\begin{array}{l}\text { Hipertermia } \\
\text { da à doença covid-19 } \\
\text { caracterizada } \\
\text { quente ao toque. }\end{array}$ & $\begin{array}{l}\text { Temperatura corporal } \\
\text { central acima dos parâ- } \\
\text { metros diurnos normais } \\
\text { devido à falha na termor- } \\
\text { regulação. }\end{array}$ & $\begin{array}{l}\text { Controle de medicamentos. } \\
\text { Controle do ambiente. } \\
\text { Controle hídrico. }\end{array}$ & $\begin{array}{l}\text { Termorregulação. } \\
\text { Definição: equilíbrio entre produção, ganho e perda } \\
\text { de calor. } \\
\text { Indicadores a serem avaliados: hipertermia; tem- } \\
\text { peratura da pele aumentada; frequência cardíaca; } \\
\text { frequência de pulso; frequência respiratória. } \\
\text { Parâmetros: } \\
\text { ( ) Gravemente comprometido; } \\
\text { ( ) Muito comprometido; } \\
\text { ( ) Moderadamente comprometido; } \\
\text { ( ) Levemente comprometido; } \\
\text { ( ) Não comprometido. } \\
\text { Outros indicadores passíveis de serem avaliados: } \\
\text { sonolência; irritabilidade. } \\
\text { Parâmetros: } \\
\text { ( ) Grave ; } \\
\text { ( ) Substancial; } \\
\text { ( ) Moderado; } \\
\text { ( ) Leve; } \\
\text { ( ) Nenhum. }\end{array}$ \\
\hline $\begin{array}{l}\text { Dor aguda relaciona- } \\
\text { da ao agente biológico } \\
\text { lesivo caracterizada } \\
\text { por autorrelato de in- } \\
\text { tensidade e de carac- } \\
\text { terísticas, evidência de } \\
\text { dor usando uma lista } \\
\text { padronizada de com- } \\
\text { portamento de dor para } \\
\text { quem não consegue se } \\
\text { comunicar verbalmen- } \\
\text { te, representante relata } \\
\text { comportamento de dor } \\
\text { e/ou alterações nas ati- } \\
\text { vidades. }\end{array}$ & $\begin{array}{l}\text { Experiência sensorial e } \\
\text { emocional desagradável } \\
\text { associada à lesão tissu- } \\
\text { lar real ou potencial, ou } \\
\text { descrita em termos de } \\
\text { tal lesão (International } \\
\text { Association for the Study } \\
\text { of Pain); início súbito ou } \\
\text { lento, de intensidade leve } \\
\text { a intensa, com término } \\
\text { antecipado ou previsível } \\
\text { e com duração menor que } \\
\text { três meses. }\end{array}$ & $\begin{array}{l}\text { Administração de analgésicos. } \\
\text { Terapia de relaxamento. }\end{array}$ & $\begin{array}{l}\text { Controle da dor. } \\
\text { Definição: ações pessoais para controlar a dor. } \\
\text { Indicadores a serem avaliados: reconhece início } \\
\text { da dor; usa medidas de alívio não analgésicas; usa } \\
\text { analgésicos conforme recomendado; usa recursos } \\
\text { disponíveis; relata dor controlada. } \\
\text { Parâmetros: } \\
\text { ( ) Nunca demonstrado; } \\
\text { ( ) Raramente demonstrado; } \\
\text { ( ) Algumas vezes demonstrado; } \\
\text { ( ) Frequentemente demonstrado; } \\
\text { ( ) Consistentemente demonstrado. }\end{array}$ \\
\hline
\end{tabular}


Quadro 4. Levantamento dos principais diagnósticos atribuídos à população infectada e com complicações agudas da covid-19.

\begin{tabular}{|c|c|c|c|}
\hline $\begin{array}{l}\text { DIAGNÓSTICO DE } \\
\text { ENFERMAGEM }\end{array}$ & DEFINIÇÃO & $\begin{array}{l}\text { INTERVENÇÕES DE } \\
\text { ENFERMEAGEM }\end{array}$ & RESULTADOS \\
\hline $\begin{array}{l}\text { Risco de choque asso- } \\
\text { ciado à hipotensão, hi- } \\
\text { povolemia, hipoxemia, } \\
\text { hipóxia, infecção, sepse, } \\
\text { síndrome da resposta } \\
\text { inflamatória sistêmica } \\
\text { (SRIS). }\end{array}$ & $\begin{array}{l}\text { Suscetibilidade a fluxo } \\
\text { sanguíneo inadequado } \\
\text { para os tecidos do corpo, } \\
\text { que pode levar a disfun- } \\
\text { ção celular que ameaça a } \\
\text { vida, que pode compro- } \\
\text { meter a saúde. }\end{array}$ & $\begin{array}{l}\text { Identificação de riscos; } \\
\text { Monitoração de sinais vitais; } \\
\text { Monitoração hídrica; } \\
\text { Oxigenoterapia; } \\
\text { Precauções contra sangramento; } \\
\text { Regulação hemodinâmica; } \\
\text { Reposição volêmica; } \\
\text { Supervisão. }\end{array}$ & $\begin{array}{l}\text { Gravidade do choque } \\
\text { Definição: gravidade dos sinais e sintomas de } \\
\text { fluxo sanguíneo inadequado para a perfusão dos } \\
\text { tecidos. } \\
\text { Indicadores a serem avaliados: saturação de oxi- } \\
\text { gênio, dióxido de carbono exalado, achados na } \\
\text { radiografia de tórax, equilíbrio ventilação/perfu- } \\
\text { são3. } \\
\text { Parâmetros: } \\
\text { ( ) Desvio grave da variação normal; } \\
\text { ( ) Desvio substancial da variação normal; } \\
\text { ( ) Desvio moderado da variação normal; } \\
\text { ( ) Leve desvio da variação normal; } \\
\text { ( ) Sem desvio da variação normal. } \\
\text { Outros indicadores passíveis de serem avaliados: } \\
\text { pressões arteriais sistólica e/ou diastólica diminuí- } \\
\text { da, frequências cardíaca e respiratória aumentadas, } \\
\text { pulso fraco ou filiforme, alteração no hemograma, } \\
\text { bioquímica e na gasometria arterial, alteração da } \\
\text { temperatura corporal, palidez, pele fria e pegajosa, } \\
\text { diminuição do débito urinário (<0,5ml/kg/min), } \\
\text { sinais de confusão, letargia, alteração do nível de } \\
\text { consciência } \text {. } \\
\text { Parâmetros: } \\
\text { ( ) Grave; } \\
\text { ( ) Substancial; } \\
\text { ( ) Moderado; } \\
\text { ( ) Leve; } \\
\text { ( ) Inexistente. }\end{array}$ \\
\hline $\begin{array}{l}\text { Risco de tromboembo- } \\
\text { lismo venoso associado } \\
\text { à comorbidade médica } \\
\text { significativa, mobilidade } \\
\text { prejudicada, admissão } \\
\text { em unidade de terapia } \\
\text { intensiva. }\end{array}$ & $\begin{array}{l}\text { Suscetibilidade ao de- } \\
\text { senvolvimento de coá- } \\
\text { gulo sanguíneo em veia } \\
\text { profunda, geralmente na } \\
\text { coxa, panturrilha ou ex- } \\
\text { tremidade superior, que } \\
\text { pode se romper e alojar- } \\
\text { se em outro vaso, o que } \\
\text { pode comprometer a saú- } \\
\text { de. }\end{array}$ & $\begin{array}{l}\text { Implementação da avaliação do } \\
\text { risco de TEV; } \\
\text { Elevação de membros inferio- } \\
\text { res; } \\
\text { Implementar e acompanhar o pa- } \\
\text { ciente com meias compressivas. } \\
\text { O Ministério da Saúde, no en- } \\
\text { tanto, orienta o uso da profila- } \\
\text { xia farmacológica em pacientes } \\
\text { sem contraindicação. No caso } \\
\text { de contraindicações, optar pela } \\
\text { profilaxia mecânica (BRASIL, } \\
\text { 2020b). }\end{array}$ & Não foram encontradas NOC's relacionadas. \\
\hline
\end{tabular}


Quadro 4 (cont.). Levantamento dos principais diagnósticos atribuídos à população infectada e com complicações agudas da covid-19.

\begin{tabular}{|c|c|c|c|}
\hline $\begin{array}{l}\text { DIAGNÓSTICO DE } \\
\text { ENFERMAGEM }\end{array}$ & DEFINIÇÃO & $\begin{array}{l}\text { INTERVENÇÕES DE } \\
\text { ENFERMEAGEM }\end{array}$ & RESULTADOS \\
\hline $\begin{array}{l}\text { Resposta disfuncional } \\
\text { ao desmame ventilatório } \\
\text { relacionada à desobstru- } \\
\text { ção ineficaz das vias aé- } \\
\text { reas, dor, história de de- } \\
\text { pendência do ventilador } \\
\text { por }>4 \text { dias, história de } \\
\text { tentativas de desmame } \\
\text { malsucedidas e caracte- } \\
\text { rizadas por desconfor- } \\
\text { to respiratório, fadiga, } \\
\text { inquietação, diaforese, } \\
\text { agitação, aumento da } \\
\text { frequência cardíaca em } \\
\text { relação aos parâmetros } \\
\text { basais ( }>\text { 20 BPM), } \\
\text { aumento da pressão ar- } \\
\text { terial em relação aos } \\
\text { parâmetros basais (> 20 } \\
\text { mm Hg), aumento sig- } \\
\text { nificativo da frequência } \\
\text { respiratória em relação } \\
\text { aos parâmetros basais, } \\
\text { cor de pele anormal, de- } \\
\text { terioração na gasometria } \\
\text { arterial em relação aos } \\
\text { valores basais, uso de } \\
\text { musculatura acessória } \\
\text { respiratória importante. }\end{array}$ & $\begin{array}{l}\text { Incapacidade de ajustar- } \\
\text { se a níveis diminuídos de } \\
\text { suporte ventilatório me- } \\
\text { cânico que interrompe e } \\
\text { prolonga o processo de } \\
\text { desmame. }\end{array}$ & $\begin{array}{l}\text { Controle da tecnologia; } \\
\text { Controle da ventilação mecâni- } \\
\text { ca; } \\
\text { Controle de vias aéreas (preven- } \\
\text { ção de pneumonia). }\end{array}$ & $\begin{array}{l}\text { Resposta ao desmame da ventilação mecânica: } \\
\text { adulto } \\
\text { Resposta ao desmame da ventilação mecânica: } \\
\text { adulto } \\
\text { Definição: } \\
\text { adaptação respiratória e psicológica ao desmame } \\
\text { da ventilação mecânica. } \\
\text { Indicadores a serem avaliados: frequência, ritmo e } \\
\text { profundidade respiratória espontânea, gasometria } \\
\text { arterial, saturação de oxigênio, equilíbrio ventila- } \\
\text { ção/perfusão3. } \\
\text { Parâmetros: } \\
\text { ( ) Desvio grave da variação normal; } \\
\text { ( ) Desvio substancial da variação normal; } \\
\text { ( ) Desvio moderado da variação normal; } \\
\text { ( ) Leve desvio da variação normal; } \\
\text { ( ) Sem desvio da variação normal. } \\
\text { Outros indicadores passíveis de serem avaliados: } \\
\text { dificuldade de respirar sozinho, dispneia em repou- } \\
\text { so ou com esforço leve, ansiedade, medo, reflexo } \\
\text { de tosse prejudicado, movimento assimétrico das } \\
\text { paredes do tórax, uso da musculatura acessória, } \\
\text { agitação, inquietação, desconforto, cianose3. } \\
\text { Parâmetros: } \\
\text { ( ) Grave; } \\
\text { ( ) Substancial ; } \\
\text { ( ) Moderado; } \\
\text { ( ) Leve; } \\
\text { () Inexistente. }\end{array}$ \\
\hline
\end{tabular}

achados anormais. Pensando nas elevadas chances de transmissão, o controle do ambiente se faz necessário para minimizá-la. São indicadores a serem avaliados: triagem dos grupos de alto risco; vigilância em saúde; investigação e notificação de contatos, disponibilidade de serviços de atenção à saúde.

Analisando-se o domínio segurança/proteção o diagnóstico de "risco para infecção" demonstrou ser adequado, mediante o surgimento da covid-19. As sugestões de intervenções de enfermagem são: monitoramento da população de risco para adquirir a doença, dos sinais e sintomas da doença na população geral e dos fatores ambientais que influenciam a transmissão da covid-19. A população deve ser informada acerca das características da doença, dos dados epidemiológicos, da sua forma de transmissão e dos métodos preventivos. As práticas de limpeza e higienização das mãos e superfícies devem ser difundidas, assim como o estabelecimento da distância mínima de $1 \mathrm{~m}$ entre as pessoas. Indicadores a serem avaliados: sinais e sintomas da doença; sinais e sintomas das complicações; estratégias para evitar exposição dos outros à doença.
O domínio conforto dispõe de um diagnóstico denominado "isolamento social", caracterizado pela necessidade do distanciamento entre as pessoas diante do elevado número de casos da doença. O enfermeiro poderá realizar diversas atividades, como: encorajar a expressão de sentimentos e o uso de mídias digitais e redes sociais como ferramenta de busca de informação e relacionamentos virtuais, estimular o indivíduo a consumir diariamente quantidades adequadas de água e líquidos. Sendo os indicadores: expressa satisfação com rotina diária; expressa satisfação com os arranjos de vida; exibe humor positivo.

Outro diagnóstico de enfermagem também localizado no domínio do conforto foi levantado, o "risco de solidão". Para prevenir o estabelecimento do diagnóstico, às atividades necessárias contemplam: o cuidado com o cuidador, buscando entender suas necessidades e sentimentos diante do isolamento. É necessário incluir a estrutura familiar no processo, determinando a carga psicológica do enfrentamento à pandemia da covid-19 para ela. Nesses casos, o recurso da arteterapia se mostra eficaz para expressão de sentimentos. São indicadores nesse caso: sensação 
de desesperança; sensação de não ser compreendido; sensação de ser excluído.

\section{Diagnósticos levantados para a população com déficit de conhecimento}

Para esta categoria, foi levantado um diagnóstico e suas possíveis intervenções, pensando-se no contexto de gestão, saúde coletiva, saúde do trabalhador e atenção primária, secundária e terciária à saúde, desta vez, considerando a necessidade de subsistência das populações durante o distanciamento social, suas repercussões e o fenômeno da "infodemia" - propagação de informações enviesadas, deturpadas e mesmo erradas em relação à saúde - que, associados ao déficit de conhecimento, podem afetar a compreensão da realidade e repercutir na saúde individual e comunitária no enfrentamento da pandemia do novo coronavírus. Neste caso, o alvo do cuidado já pode, ou não, ter adoecido por covid-19.

Dentro do domínio de enfrentamento/tolerância ao estresse foi levantado o diagnóstico de "enfrentamento ineficaz". Sugestões de intervenções de enfermagem para essa situação: determinar a adequações financeiras e alimentares, do paciente durante o período enfrentado, visando informar e apoiar o indivíduo/familiares sobre acesso a meios de assistência social disponíveis nesse período. Além de estabelecer uma relação interpessoal pautada na confiabilidade, visando proporcionar espaços de discussão de ideias delirantes, encorajá-lo a verbalizar também com os demais cuidadores para aumentar a rede de apoio e monitorar a capacidade do autocuidado e estado físico. Nesta situação dever ser avaliados: ameaça percebida à saúde; preocupação relativa a potenciais complicações

\section{Diagnósticos levantados para o paciente infectado pela covid-19}

Foram levantados três diagnósticos e suas possíveis intervenções. $\mathrm{O}$ alvo do cuidado entrou contato com o agente infeccioso e recebeu diagnóstico clínico-epidemiológico ou laboratorial para covid-19.

$\mathrm{O}$ primeiro diagnóstico definido se encontra no domínio eliminação e troca e consiste na "troca de gases prejudicada". Destaca-se que a função pulmonar do paciente acometido pela covid-19 pode estar comprometida, de forma que o profissional de enfermagem tem a responsabilidade de realizar intervenções diante da identificação desse problema. As intervenções de enfermagem elencadas são: monitorar estado respiratório e oxigenação; realizar ausculta do aparelho respiratório para identificação de sons anormais; administrar medicamentos para aliviar os sintomas. Cita-se ainda o monitoramento de sinais de choque e da gasometria arterial. Nessa circunstância deve ser ponderado: saturação de oxigênio; achados na radiografia de tórax; equilíbrio ventilação-perfusão.

O domínio de segurança/proteção contém o segundo diagnóstico, sendo ele a "hipertermia" associada à infecção pelo novo coronavírus. Para este problema, as intervenções sugerem o monitoramento dos sinais vitais e da desidratação, administração de terapia endovenosa, evitar exposição excessiva a diferentes temperaturas. A administração de antipiréticos deve seguir as orientações para o tratamento de pacientes acometidos pela covid-19 definidas pelo Ministério da Saúde 3 . Pode ser analisado: hipertermia; temperatura da pele aumentada e sinais vitais.

O terceiro diagnóstico estabelecido foi "dor aguda", e se encontra no domínio conforto. Algumas sugestões de intervenções são: administração de analgésicos; verificar local, características, qualidade e gravidade da dor; administrar analgésicos em horários fixos para prevenir picos e depressões da analgesia; criar um ambiente calmo e sem interrupções com luzes fracas e temperatura confortável, e usar o relaxamento como a estratégia adjuvante com medicamentos para a dor. Indicadores a serem ponderados: reconhece início da dor; usa medidas de alívio não analgésicas e se usa analgésicos conforme recomendado.

\section{Diagnósticos levantados para a população infectada e com complicações agudas da covid-19}

Foram levantados três diagnósticos e suas possíveis intervenções para esta categoria. $\mathrm{O}$ alvo do cuidado adoeceu por covid-19 e manifesta complicações agudas relacionadas à infecção.

O primeiro diagnóstico encontra-se no domínio segurança e proteção, sendo "risco de choque". As propostas de intervenções de enfermagem são: identificar riscos ao paciente (biológicos, comportamentais ou inter-relacionais), monitorar os sons pulmonares, oximetria de pulso alvo entre $95 \%$ e $98 \%{ }^{16}$. Avaliar a cor, temperatura, umidade da pele e cianose central e periférica, ingestão e eliminação. A administração de oxigênio surge como uma intervenção importante nesses casos, devendo ser realizada através de um sistema aquecido e umidificado ${ }^{3}$. Para isso deve ser avaliado: saturação de oxigênio, dióxido de carbono exalado e equilíbrio ventilação/perfusão.

Outro diagnóstico pontuado é o "risco de tromboembolismo venoso". As intervenções indicadas são: implementação da avaliação do risco de TEV (tromboembolismo venoso), elevação de membros 
inferiores, implementação e acompanhamento do paciente com meias compressivas ${ }^{17}$.

No domínio atividade e repouso está o terceiro diagnóstico de enfermagem, sendo a "resposta disfuncional ao desmame ventilatório". As sugestões de intervenções incluem: substituir equipamentos de assistência ao paciente que estiverem sujos, usar alterações nos dados obtidos com a máquina para a reavaliação do paciente de covid-19 em tentativa de desmame ventilatório, posicionar o paciente de modo a maximizar o potencial ventilatório, encorajar respiração lenta e profunda, administrar tratamentos com nebulizadores ultrassônicos, posicionar o paciente entre $30^{\circ}$ e $45^{\circ}$ graus para aliviar a dispneia por meio da redução da pressão das vísceras abdominais sobre o diafragma e a oxigenação ${ }^{16}$. Indicadores para serem avaliados são: sinais vitais, saturação de oxigênio e equilíbrio ventilação/perfusão.

As pesquisas sobre o novo coronavírus são recentes e a cada dia surgem mais informações, dessa forma o trabalho foi realizada com o material disponível até o momento. As limitações do estudo referem-se à amostra, visto que foram incluídos apenas os artigos e documentos disponíveis gratuitamente.

\section{Conclusão}

Este estudo permitiu identificar os principais diagnósticos de enfermagem atribuídos aos pacientes mediante a situação da pandemia de covid-19 no Brasil. Para cada diagnóstico elencado definiramse as respectivas intervenções e resultados, frisando a necessidade de avaliação particular dos casos e cenários que podem existir, durante a prática clínica do profissional de enfermagem nos diferentes níveis de atenção.

As implicações desse trabalho para a enfermagem ocorrem pela exposição de importantes etapas do processo de enfermagem, refletidas pela literatura mais recente vislumbrando a aplicabilidade na conjuntura do covid-19.Possibilitandoaos profissionais de enfermagem da linha de frente informações essências para uma assistência em saúde efetiva. Dada a sua importância, a elaboração e atribuição dos diagnósticos de enfermagem não pode ser dissociada do processo de enfermagem, uma vez que suas etapas são interdependentes, sendo este fundamental para o processo de tomada de decisão e a definição de condutas futuras.

\section{Referências}

1. Zhang J, Dong X, Cao Y, Yuan Y, Yang Y, Yan Y et al. Clinical characteristics of 140 patients infected with SARS-CoV-2 in Wuhan, China. Allergy [Internet]. 2020 [cited 2020 Apr. 22];75:1730-1741. Available from: < https://bestpractice.bmj.com/topics/en-gb/3000201>.
2. Beeching NJ, Fletcher ET, Flower R. Coronavírus disease 2019 (COVID-19). BMJ, Best Practice [Internet]. 2020 [cited 2020 Apr. 22]. Available from: <https://bestpractice.bmj.com/topics/en-gb/3000168>

3. Ministério da Saúde, Secretaria de Ciência, Tecnologia, Inovação e Insumos Estratégicos em Saúde - SCTIE [Internet]. Diretrizes para diagnóstico e tratamento da COVID-19. Brasília: Ministério da Saúde, Versão 1. 2020. Disponível em: <https://portalarquivos.saude.gov.br/images/ pdf/2020/April/18/Diretrizes-Covid19.pdf>.

4. Johns Hopkins University. Coronavírus Resource Center [Internet]. Baltimore (MD) 2020. Available from: <https://coronavirus.jhu.edu/map. html>.

5. Tannure MC, Pinheiro AM. SAE: Sistematização Da Assistência De Enfermagem. Guia Prático. 2a ed. Rio de Janeiro (RJ): Guanabara Koogan; 2010 .

6. Conselho Federal de Enfermagem (Brasil). Resolução $n^{\circ} 358$, de 15 de outubro de 2009. Dispõe sobre a Sistematização da Assistência de Enfermagem e a implementação do Processo de Enfermagem em ambientes, públicos ou privados, em que ocorre o cuidado profissional de Enfermagem, e dá outras providências [Internet]. Diário Oficial da União (DF). 2009 [acesso em 22 Abr. 2020]. Disponível em: <http://www.cofen.gov.br/resoluo-cofen3582009 4384.html>.

7. Herdman TH, Kamitsuru S. Diagnósticos de enfermagem da NANDA I: definições e classificação 2018-2020. 11a ed. Porto Alegre (RS): Artmed; 2018.

8. Bulechek GM, Butcher HK, Dochterman JM, Wagner CM. NIC, Classificação das Intervenções de Enfermagem. 6a ed. São Paulo (SP): Elsevier; 2016

9. De Mello RRPB, Villardi RM, Mello SCRP, Miranda MG. Desafios no acesso à água e saneamento básico no Brasil e controle da COVID-19. Rev. Augustus [Internet]. 2020 [acesso 22 Abr. 2020]. Disponível em: $<$ https:// revistas.unisuam.edu.br/index.php/revistaaugustus/article/view/573/303>.

10. O Globo. Cerca de 18,4 milhões de brasileiros não recebem água encanada diariamente, aponta IBGE [Internet]. 2020 [acesso 30 Jun. 2020]. Disponível em: <https://g1.globo.com/economia/noticia/2020/05/06/cercade-184-milhoes-de-brasileiros-nao-recebem-agua-encanada-diariamenteaponta-ibge.ghtml>.

11. Instituto Brasileiro de Geografia e Estatística (BR). Síntese de Indicadores Sociais 2015: Uma análise das condições de vida da população brasileira [Internet]. Rio de Janeiro: IBGE, 2016. Disponível em $<$ https:// ibge.gov.br/estatisticas/sociais/saude.html>.

12. Nascimento IS, Santos PC. A normalidade da desigualdade social e da exclusão educacional no Brasil. Caderno de Administração [Internet]. 2020 [acesso 30 Jun. 2020];28, 122-130. Disponível em: < http://periodicos.uem. br/ojs/index.php/CadAdm/article/view/53834>.

13. Alfaro-Lafevre R. Aplicação do Processo de Enfermagem: Promoção do Cuidado Colaborativo. 5a ed. Porto Alegre (RS): Artmed; 2005.

14. Machado MFAS, Monteiro EMLM, Queiroz DT, Vieira NFC, Barroso MGT. Integralidade, formação de saúde, educação em saúde e as propostas do SUS: uma revisão conceitual. Ciênc. saúde coletiva [Internet]. 2007 [acesso 09 Maio 2020]; 12( 2 ): 335-342. Disponível em: <http://www.scielo.br/ scielo.php?script=sci_arttext\&pid=S1413-81232007000200009\&lng=en $>$.

15. Barros ALBL. Anamnese e exame físico: avaliação diagnóstica de enfermagem no adulto. 3 a ed. Porto Alegre: Artmed, 2016.

16. Conselho Regional de Enfermagem ES (Brasil). Diagnóstico de enfermagem em casos de coronavírus [Internet]. 2020. [acesso 20 Mai. 2020]. Disponível em: <http://www.coren-es.org.br/diagnostico-de-enfermagemem-casos-de-coronavirus-e-covid-19 21788.html>.

17. Barp M, Carneiro VSM, Amaral KVA, Pagotto V, Malaquias SG. Cuidados de Enfermagem na prevenção do tromboembolismo venoso: revisão integrativa. Rev Eletr Enf. [Internet]. 2018 [acesso 20 Mai. 2020]. Disponível: $\quad<$ https://docs.bvsalud.org/biblioref/2018/11/964364/v20a14. pdf $>$. 